\title{
GLÁUKS
}

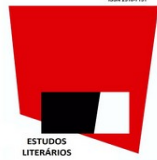

\section{Entrevista com Alexandre Vidal Porto}

\author{
Joelma Santana Siqueira (Universidade Federal de Viçosa)
}

Vivaldo Andrade dos Santos (Georgetown University)

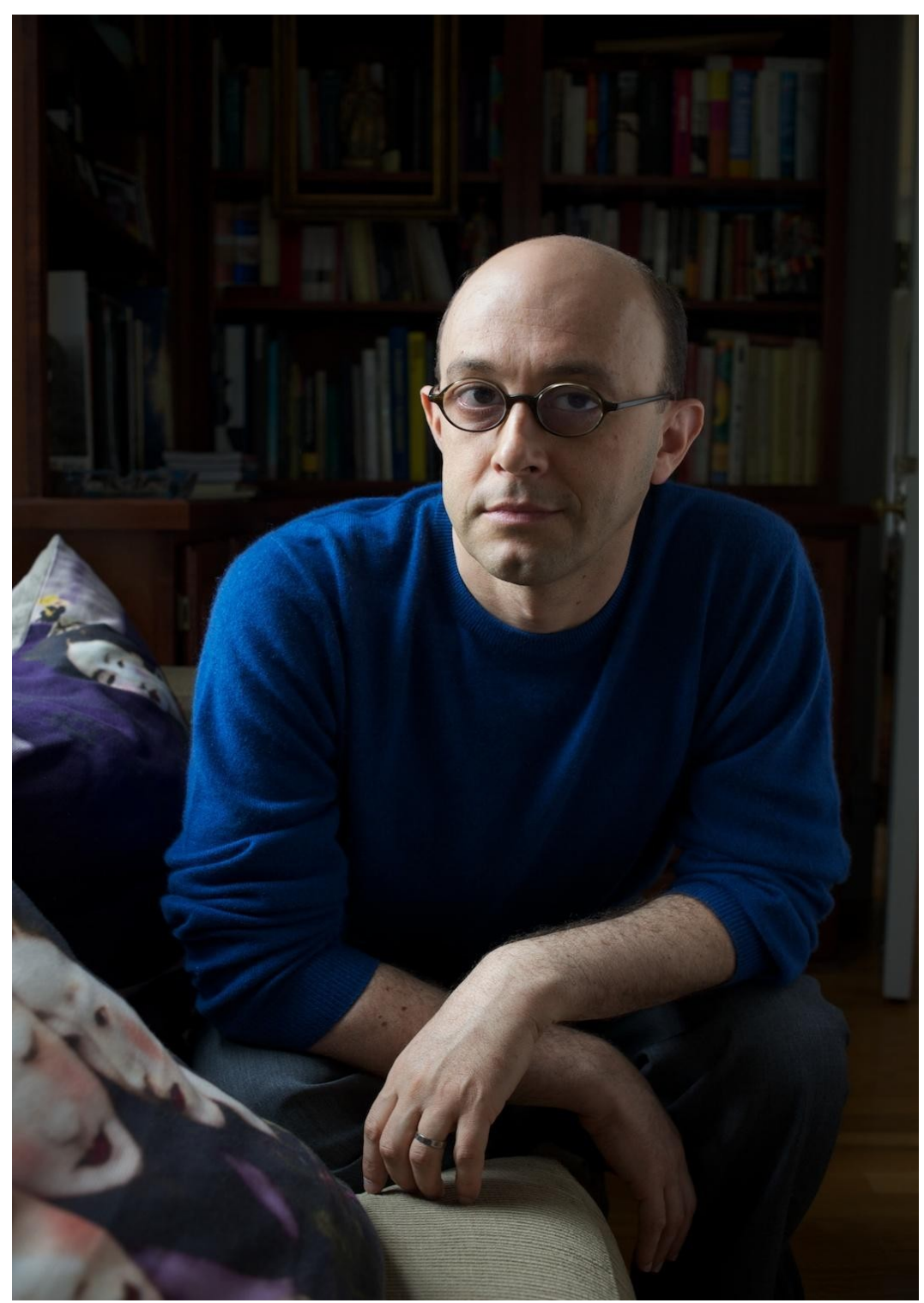

Fonte: Arquivo pessoal do escritor.

Gláuks: Revista de Letras e Artes - jul/dez 2020 - v. 20, n. 2 
Alexandre Vidal Porto - É escritor e diplomata. Passou a infância em São Paulo e a adolescência em Fortaleza. Viveu em Brasília, Nova York, Santiago do Chile, Cambridge, Washington, Cidade do México e Tóquio. É mestre em direito pela Universidade de Harvard e colunista do jornal Folha de São Paulo. Autor de três romances: Matias na cidade (Record, 2005); Sergio Y. vai à América (Companhia das Letras, 2014; Europa Editions, 2016; EO Edizioni, 2016), ganhador do Prêmio Paraná de Literatura; e Cloro (Companhia das Letras, 2018), semifinalista do prêmio Oceanos 2019 e finalista do prêmio Jabuti 2019. Atualmente, vive em Frankfurt e trabalha na reedição de Matias na cidade (Companhia das Letras, 2022), e no seu próximo romance, ainda sem título.

1. Prezado Alexandre Vidal Porto, somos muito gratos a você por nos conceder essa entrevista para o presente dossiê da Gláuks dedicado ao tema "A literatura brasileira no exterior". Para iniciarmos, pedimos que nos fale sobre como é escrever e publicar literatura no Brasil.

Escrever e publicar literatura no Brasil é sacrificado, porque o mercado de livros é limitado e, salvo pouquíssimas exceções, não é possível, por razões financeiras, viver da escrita literária. Então, no Brasil, para a maioria das pessoas, a dedicação exclusiva à literatura parece inviável por questões de sobrevivência, pura e simplesmente. O escritor brasileiro tem sempre de se desdobrar como jornalista, funcionário público, tradutor, professor, ou depender de amigos ou familiares. No entanto, tenho a impressão de que, ainda que em menor escala, o mesmo se passa em países com mercados mais amplos e sólidos, e uma minoria consegue se sustentar como escritor, apenas. Paradoxalmente, apesar dessas dificuldades, a impressão que eu tenho é que, no Brasil, nunca se publicou tanto como agora, porque as plataformas digitais se popularizaram. A identificação dos leitores e a distribuição da obra é que se tornaram o desafio de quem publica no Brasil hoje.

Gláuks: Revista de Letras e Artes - jul/dez 2020 - v. 20, n. 2 
2. Você considera que há diferenças que mereçam ser destacadas entre a recepção que sua obra tem no Brasil e a que tem no exterior?

Sim, há diferenças. A aceitação maior da minha obra é no Brasil, porque, para começar, meus três romances estão disponíveis em português, ao passo em que, no exterior, isso não acontece. Então a integralidade da minha literatura pode ser avaliada melhor no Brasil. Além disso, sobretudo no caso do mercado norte-americano, existe preconceito em relação a traduções, o que limita o alcance. O mercado para obras traduzidas é pequeno, e a competição é enorme. Fui editado por casas prestigiosas no mercado anglófono, que investiram em mim em termos de promoção. Fui finalista de alguns prêmios importantes no exterior, mas, mesmo assim, considero que a recepção foi limitada.

\section{Qual a importância da tradução, sobretudo, para o escritor que escreve em português?}

Para quem escreve em português e quer ser publicado no exterior, a figura do tradutor é fundamental. Seja pela mera existência material da obra, como tradução, seja para a divulgação da obra junto ao mercado editorial do país em que se publica. A questão é que o mercado de tradutores de português é limitado. Minha impressão é que os bons tradutores estão sempre sobrecarregados.

\section{Quais são os desafios para ser publicada no exterior ou ser traduzida para outra língua?}

O desafio principal é o acesso. Como chegar ao editor estrangeiro, que, na grande maioria das vezes, não lê português? É importante ter amostras do texto traduzido, o que já envolve custos de tradução. Geralmente, esse acesso acontece por intermédio de agentes, nas

Gláuks: Revista de Letras e Artes - jul/dez 2020 - v. 20, n. 2 
feiras literárias internacionais, ou seja, é preciso quase sempre ter um agente ou algum contato que apresente a obra a quem poderia publicá-la no exterior.

5. "Traduttore, traditore". Como é ler a literatura brasileira traduzida para outro idioma? Destacaria algum exemplo?

Não leio traduções do português, mas comenta-se que muitas das traduções de obras importantes de nossa literatura para o inglês são sofríveis. Observo, porém, que existe uma geração emergente de tradutores muito competentes, especialmente para a língua inglesa, como Bruna Dantas Lobato, Daniel Hahn, Eric Becker, Zoë Perry, entre outros. Gostaria de chamar a atenção para a excelente nova tradução de Memórias Póstumas de Brás Cubas, feita pela Flora Thomson-DeVeaux para a Penguin Classics, e para a de Grande sertão: Veredas, em elaboração pela grande Alison Entrekin.

6. Existe uma "literatura nacional”, presa a um país, a uma região, a uma língua?

Acredito que uma literatura escrita numa mesma língua, num mesmo espaço geográfico e num mesmo período histórico tem, sim, traços característicos comuns. Não sei se isso a caracterizaria como "nacional", mas acho que escritores que escrevem na mesma língua e no mesmo período, acabam compondo um retrato que traduzirá o espírito de um país - ou, se você quiser, de uma "nação".

7. Seu fazer literário busca responder a alguma urgência presente na realidade social brasileira que você gostaria de destacar?

Gláuks: Revista de Letras e Artes - jul/dez 2020 - v. 20, n. 2 
Quando escrevo, não me preocupo diretamente em responder às urgências da sociedade brasileira, mas algumas respostas acabam aparecendo naturalmente, em função de eu ser brasileiro e a maioria de meus personagens morar no Brasil. Então, o que você chama de "urgências da sociedade brasileira" é o dia-a-dia que eles vivem, e isso acaba transparecendo na minha literatura. Eu admiro quem consegue fazer um ativismo literário mais direto e estridente. Meus livros falam de questões sociais urgentes, como desigualdade, discriminação, preconceito, minorias. Mas meu estilo pede algo mais subliminar: as questões sociais surgem como pano de fundo, como parte do cenário e do quotidiano dos personagens, não como protagonistas da história.

Gláuks: Revista de Letras e Artes - jul/dez 2020 - v. 20, n. 2 